\title{
Vascular Remodeling in Coronary Artery Disease
}

\author{
Carlo Di Mario, Peter N. Ruygrok, and Patrick W. Serruys \\ Intracoronary Imaging Laboratory and the Cardiac Catheterization Laboratory, Division of Cardiology, \\ Thoraxcenter, Erasmus University, Rotterdam, The Netherlands
}

Summary: Traditionally, the diagnosis of significant coronary atherosclerotic disease has relied on angiographic techniques. Both histologic analyses and, more recently, intravascular ultrasonography techniques have revealed that a significant atherosclerotic plaque load may be present in epicardial coronary arteries without significant luminal narrowing, consistent with compensatory vessel enlargement or remodeling. In patients with coronary atherosclerosis, more limited structural changes are present in the smaller resistance arterioles, whereas a decrease in luminal area with an increase in wall thickness and perivascular fibrosis are the characteristic structural changes observed in resistance arteries in the presence of systemic hypertension. Further, functional changes, such as impairment of endothelium-mediated vasodilation, are present in epicardial and resistance vessels of patients with coronary atherosclerosis and may influence the pro- gression of this disease and development of ischemic syndromes. The introduction of two-dimensional intravascular and Doppler ultrasonography enables us to study in vivo these morphologic and functional changes. In this article, the knowledge acquired in humans on the mechanisms and clinical relevance of vascular remodeling with the use of these two ultrasonography-based techniques is reviewed. The possibility of using pharmacologic interventions to improve or normalize the vascular response to endothelium-dependent and independent vascular interventions is discussed, with special attention to the efficacy of the inhibition of the angiotensin-converting enzyme. Key Words: Endothelium-derived relaxing factorAngiotensin-converting enzyme inhibitors-Quantitative angiography-Intracoronary ultrasonography-Doppler ultrasonography-Atherosclerosis.
Coronary angiography has until recently remained unchallenged as the gold standard in the diagnosis of obstructive coronary artery disease, and on the basis of angiographic findings, management decisions on medication, angioplasty, or coronary artery surgery are made. Pathologic studies have shown that a considerable atherosclerotic plaque load can be present in angiographically normal arterial segments. Further, angiography is unable to study alterations of flow induced by changes in the distal coronary vasculature.

Two-dimensional intracoronary ultrasonography provides a cross-sectional view of the vessel lumen and wall comparable to that of in vivo histology and allows quantitative measurement of the lumen and plaque area. Intracoronary Doppler ultrasonography can selectively measure flow velocity in baseline conditions and after pharmacologic stimuli, and detect flow alterations due to the presence of a flow-limiting epicardial stenosis or to the impairment of the coronary microvasculature.

The introduction of these two techniques enables us to study in vivo, in the catheterization laboratory, the arterial remodeling that occurs in conductance and resistance vessels in patients with coronary atherosclerosis and in those who have risk factors for this disease. In this article, the mechanisms and clinical relevance of the remodeling process in coronary epicardial and resistance vessels are discussed. The modalities of assessment of these morphologic and functional changes and the effects of pharmacologic interventions are reviewed.

\section{MECHANISMS OF VASCULAR REMODELING}

\section{Remodeling in epicardial arteries}

The term remodeling has been used with regard to changes in ventricular dimensions following in-

Address correspondence and reprint requests to Dr. P. Serruys at Cardiac Catheterization Laboratory, Division of Cardiology, Thoraxcenter, Ee 2332, Erasmus University, P.O. Box 1738, 3000 DR Rotterdam, The Netherlands. 
farction (1). More recently, this term has been applied to the vascular changes observed in atherosclerosis and systemic arterial hypertension (2).

The enlargement of coronary arteries in response to luminal encroachment by atherogenic plaque was first observed in monkeys in response to an atherogenic diet (3). This phenomenon was first reported to occur in humans by Glagov et al. (4). His group studied histologic sections of the left main coronary artery in 136 hearts obtained at autopsy. The hearts were fixed under pressure before intracoronary injection with a barium mixture, and radiographs in two projections were made. The arteries were then sectioned and histologically examined. It was noted that the area circumscribed by the internal elastic lamina increased as the area of the plaque contained within the lumen increased, thus preserving luminal area up to a critical point ( $30-40 \%$ area stenosis). At this point the artery appeared unable to continue to enlarge at a rate sufficient to prevent significant luminal narrowing. Similar findings were noted by Stiel et al. (5) in the proximal left anterior descending and right coronary arteries. He concluded that compensatory enlargement significantly influenced the in vitro angiographic assessment of a coronary lesion with underestimation up to a degree of $50 \%$ area stenosis.

The limitations of in vitro techniques and fixation methods were overcome by the introduction of intravascular ultrasonography imaging (IVUS). Fol- lowing characterization of intracoronary atherosclerotic lesions by IVUS $(6,7)$ researchers were able to proceed in comparing angiography and ultrasonography in vivo. Angiography portrays the vessel lumen as a silhouette, a perspective that is unable to reflect the complex eccentric and irregular nature of coronary atherosclerotic disease, whereas IVUS enables the visualization of wall morphology and intramural anatomy as well as luminal dimensions. Atheromatous involvement of an artery can be identified on ultrasonography images even in segments that appear to be angiographically normal (Figs. 1 and 2). Several studies have shown that a significant atherosclerotic plaque area of up to $30-45 \%$ can be present in segments of coronary artery that appear angiographically normal (8-10), suggesting that arterial enlargement or remodeling occurs in early atherosclerotic lesions. We have also studied this phenomenon and have found that atherosclerotic involvement at the site identified by quantitative coronary angiography as the normal reference segment is common, with only $12 \%$ of these sites being disease-free.

In 43 patients observed prior to coronary interventions, the mean plaque area at the site of the angiographic reference occupied $50 \pm 11 \%$ (J. Escaned et al., unpublished observations) of the total area inside the external elastic membrane (plaque plus lumen area). Therefore, angiography may underestimate the original dimension of the normal

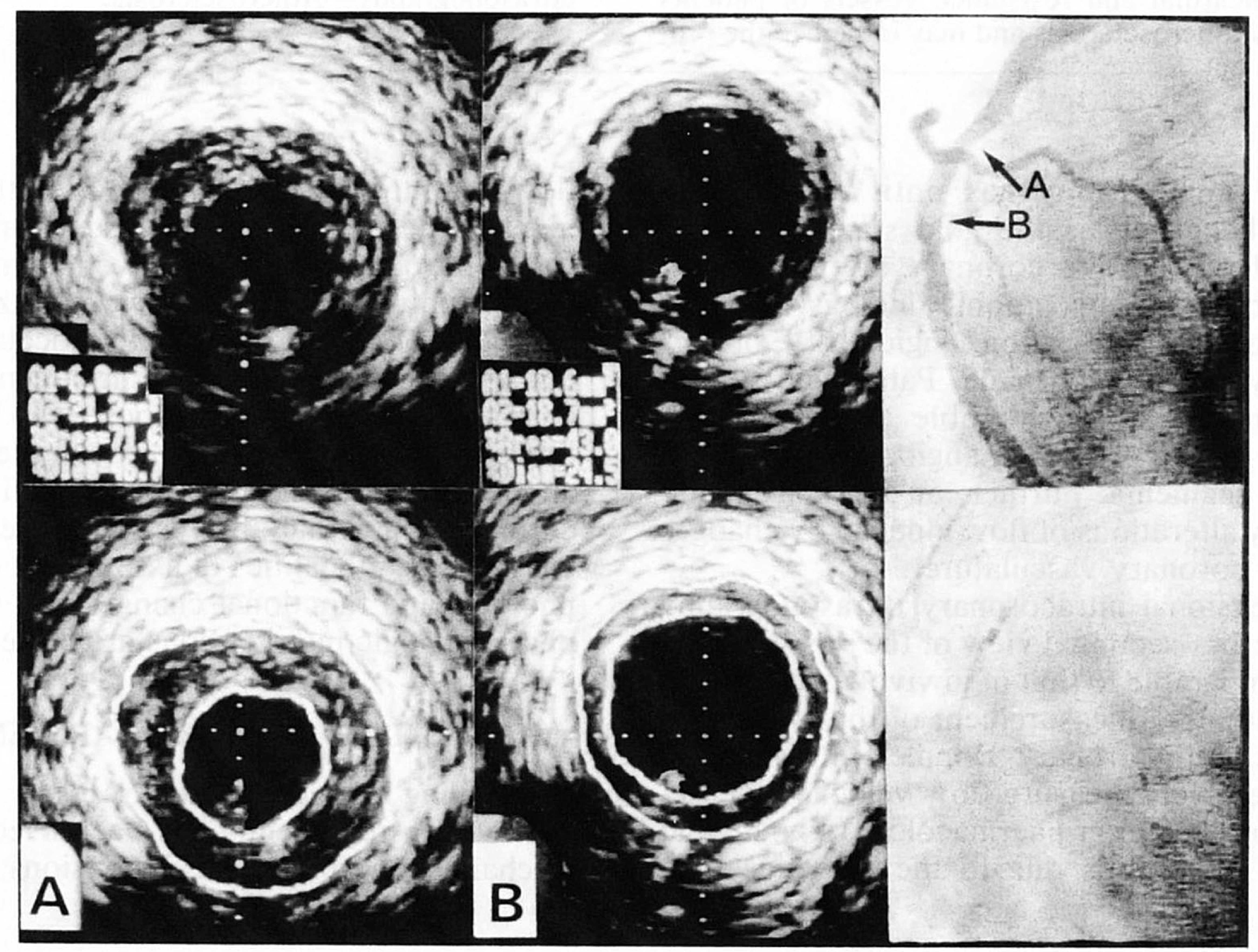

FIG. 1. Cross-sectional intracoronary ultrasonography images obtained from a right coronary artery showing a segment of mild stenosis (A) and an angiographically normal segment (B). At points A and B, 71.6 and $43 \%$ of the cross-sectional area, respectively, are occupied by a concentric atherosclerotic lesion. 


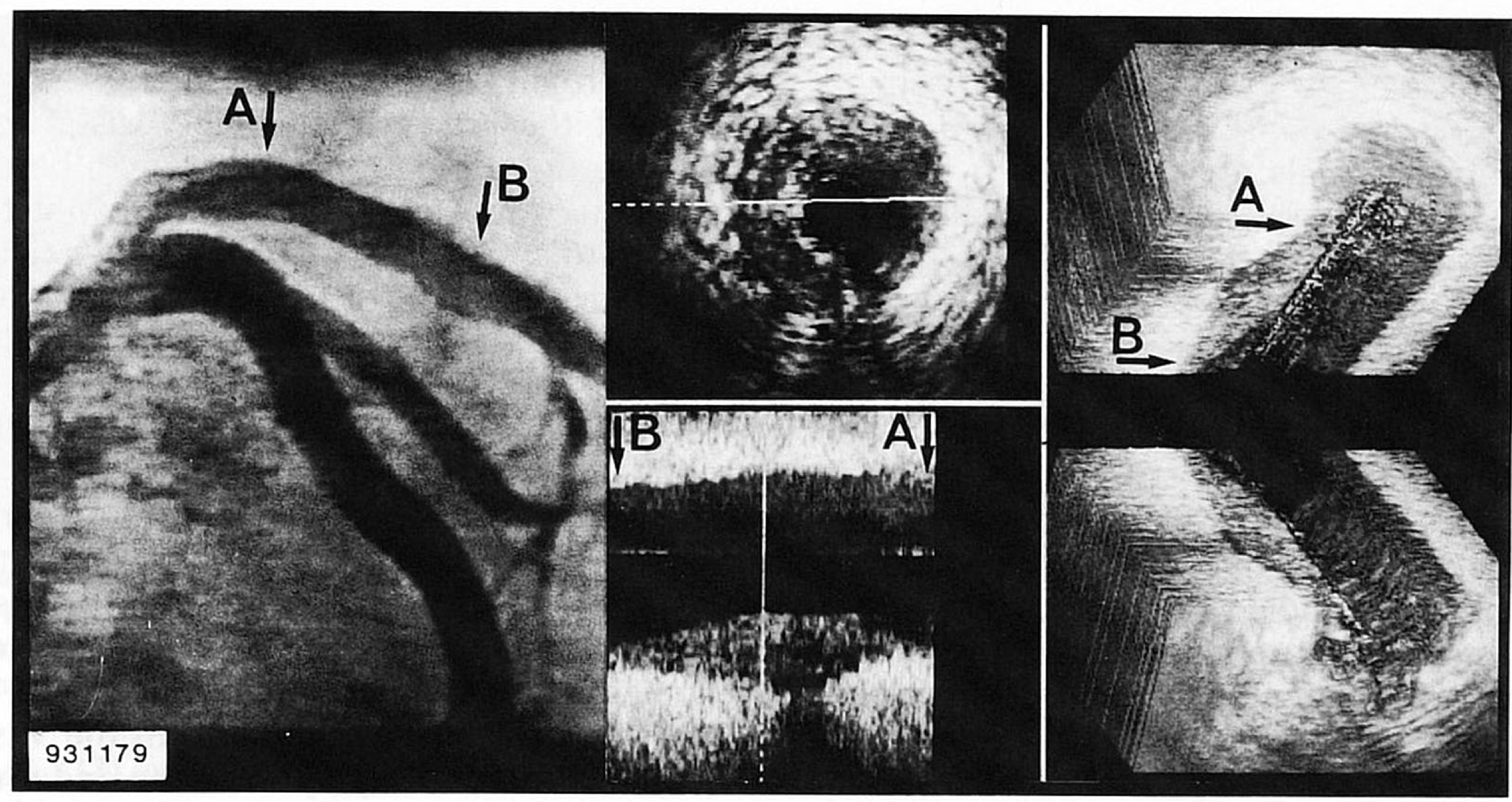

FIG. 2. A digital arteriogram of an angiographically normal segment of a left anterior descending artery from within which ultrasonography images were recorded and reconstructed as a three-dimensional image [start and end points (A, B) of the reconstructed segment are indicated in both images for comparison]. The resulting reconstructed segment of artery is opened longitudinally to visualize the internal structure of the vessel segment. Despite the luminal diameter remaining constant, the internal vessel diameter is increased at the site of maximum plaque load (continuous vertical line in middle lower panel).

lumen in the patient group with severe and diffuse atherosclerotic involvement. This explains the poor correlation of relative angiographic measurements of stenosis severity (i.e., the percentage of diameter stenosis) with functional status and evidence of reversible myocardial ischemia after exercise or pharmacologic stressors $(11,12)$. These findings suggest that the start of the stenosis identified by automated analysis systems represents the point where compensatory vessel enlargement fails to preserve luminal dimensions.

This knowledge may explain the minimal changes in lumen area observed in large angiographic studies aimed at assessing progression or regression of atherosclerotic disease after pharmacologic or dietary interventions (13). Animal studies have demonstrated the superiority of IVUS over quantitative angiography to assess regression of atherosclerosis in rabbits fed an atherogenic diet $(14,15)$. Both mechanical and neurohumoral mechanisms have been proposed to explain the phenomenon of arterial remodeling in coronary atherosclerosis. It has been suggested that developing atherosclerotic plaque, which is usually eccentric, may destroy or compress underlying structures, causing wall atrophy or degradation of mural connective tissue fibers and resulting in the outward bulging of plaque and the underlying vessel wall (16). Alternatively, coronary artery remodeling may be due to an increase in shear stress (force per unit area) that occurs as lumen area decreases. Vita et al. demonstrated in humans that angiographically normal coronary arteries dilate as shear stress increases (17). He suggested that in response to local shear stress at the endothelial surface, vasodilation occurs, probably by an endothelium-dependent mechanism tending to reduce the shear stress. Thereby a local feedback mechanism is established and appears to control shear stress under conditions of increased flow.

In coronary atherosclerosis it is suggested there is a failure of the control mechanism, perpetuating functional disturbances in the coronary endothelium and progression of atherosclerosis. This theory would be in keeping with compensatory expansion in mild coronary artery disease with a failure to maintain luminal dimensions in more severe concentric lesions. Others have suggested that in less severe disease, non-affected regions of vessels with eccentric lesions or neighboring segments may release vasodilatory compounds, thus leading to expansion of the uninvolved segment of vessel wall $(6,18)$.

\section{Changes in coronary resistance vessels}

Approximately $75 \%$ of resistance to coronary blood flow resides in arterioles $<200 \mu \mathrm{m}$ in diameter (19). Despite the continuous progress in image quality and increase in resolution, angiography is unable to visualize these in small-caliber arterioles. Miniaturization of ultrasonography transducers has facilitated the manufacture of imaging catheters as small as $1 \mathrm{~mm}$ in diameter, a dimension that allows the visualization of severe stenosis or of distal coronary vessels but that is insufficient to explore the resistance vessels. Further, minimal pathologic changes can be observed in the arterioles of patients with diffuse and severe atherosclerosis of the large coronary arteries. In a porcine model of experimental atherosclerosis induced by a high-cholesterol and -corn oil diet, atherosclerotic lesions are not 
observed in vessels with a diameter $<500 \mu \mathrm{m}$ (20). However, arterioles isolated from these animals lack the functional responses to change in flow observed in control animals.

More specific structural abnormalities characterize the resistance vessels in the presence of systemic hypertension. Chronic hypertension produces marked intimal hyperplasia and medial thickening in both conductance and resistance vessels. The resultant reduction in luminal diameter and subsequent diminished flow in resistance vessels may partly explain ischemic syndromes in patients with normal epicardial arteries. In a human study, Schwartzkopf et al. studied intramyocardial arterioles $<100 \mu \mathrm{m}$ diameter) obtained by right ventricular biopsies in 14 patients with arterial hypertension and angina pectoris despite the presence of normal epicardial arteries (21). It was observed that wall thickening and an increased amount of interstitial fibrosis were present and inversely related to the maximal vasodilatory capacity of the coronary system.

Recent studies have shown that a rearrangement of the same amount of material around a smaller lumen, rather than wall hyperplasia, is the likely cause of the abnormal vascular structure seen in the resistance vessels of patients with essential hypertension (2). In resistance vessels, therefore, the process of vascular remodeling seems to be the inverse of that described in epicardial arteries. Although the structural changes of the resistance coronary vessels cannot be studied in vivo using morphologic techniques, indirect evidence of this process can be obtained by the measurement of the maximal hyperemic flow or minimal vascular resistance.

The introduction and refinement of intracoronary Doppler ultrasonography has superseded more cumbersome methods such as coronary sinus thermodilution and videodensitometry (22) in the assessment of coronary flow and coronary flow resistance in the catheterization laboratory (Fig. 3). By quantitative angiography (23) or two-dimensional intracoronary angiography (24) the cross-sectional area of the artery immediately distal to the radiopaque tip of the Doppler wire can be determined and thus the Doppler-derived flow velocity converted to an estimate of coronary arterial flow (Fig. 4). With a measure of the mean aortic pressure, the coronary flow resistance can also be calculated.

\section{Endothelial dysfunction in the coronary circulation}

The continuous lining of endothelium that cover the entire vascular system is not only a mechanical barrier but represents a complex organ that modulates the tone of underlying smooth muscle, maintains a nonadhesive luminal surface, and mediates homeostasis, cellular proliferation, and inflammatory and immune mechanisms in the vascular wall (25). In the coronary system, the endothelium also regulates myocardial perfusion by modulating vasomotor tone in both conduit and smaller-resistance vessels through the release of endothelium-derived relaxing and contracting factors (26).

The in vitro observations of Furchgott and Zawadzki (27) and the in vitro and in vivo reports from Palmer et al. (28) and Vallance et al. (29) have identified that an endothelium-derived relaxing factor is released in response to physiologic and pathologic stimuli (increase in wall shear stress, serotonin, bradykinin, histamine, thrombin, sympathetic stimulation, acetylcholine, and endotoxins). Endothelial damage, leading to a decreased formation or release of nitric oxide from its precursor L-arginine, or reduced penetration due to the presence of subendothelial intimal thickening, are possible explanations of the impairment of endothelium-mediated vasodilatation observed in patients with systemic hypertension (30), hypercholesterolemia, diabetes mellitus (31), and atherosclerosis (32).

The presence of paradoxical vasoconstriction induced by acetylcholine has been shown in coronary patients at sites of severe stenosis or moderate wall

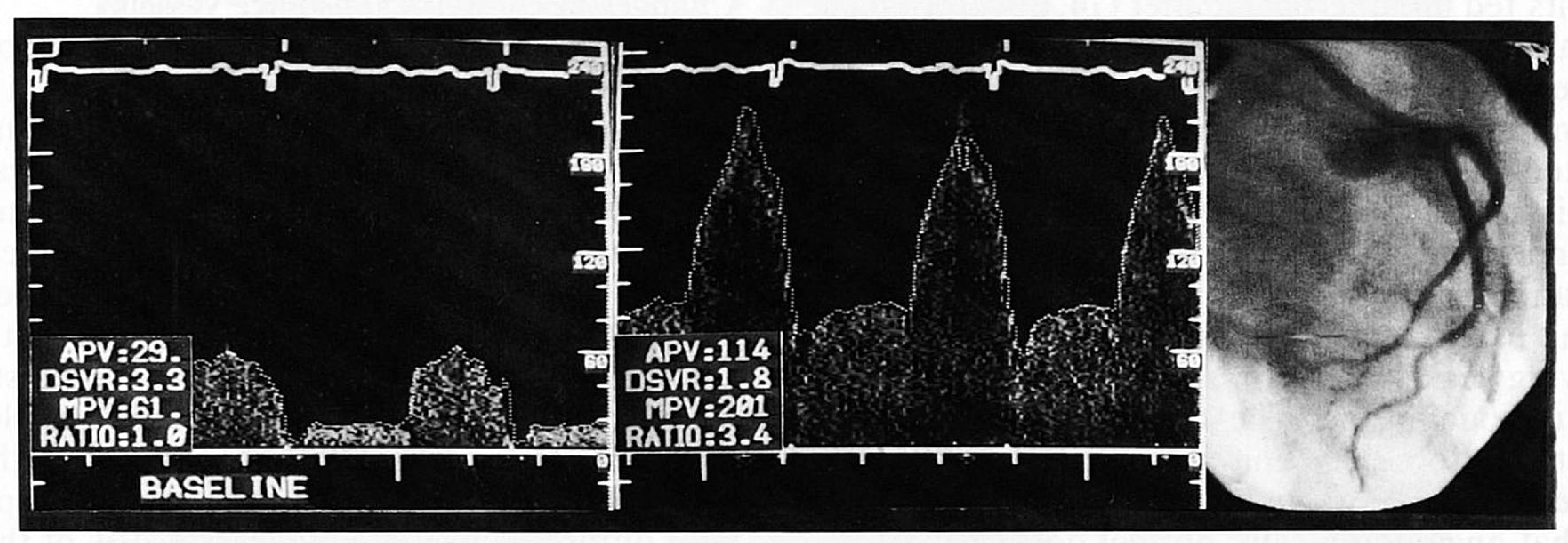

FIG. 3. Flow velocity measurement employing a 0.014-in. Doppler guide wire (Cardiometrics, Mountain View, CA, U.S.A.) in a normal porcine left circumflex artery, angiographically displayed in the right panel. The middle panel shows a normal hyperemic response following an intracoronary injection of adenosine, with a more than threefold increase in average peak velocity (APV) and maximum peak velocity (MPV). DSVR, diastolic to systolic velocity rate. 


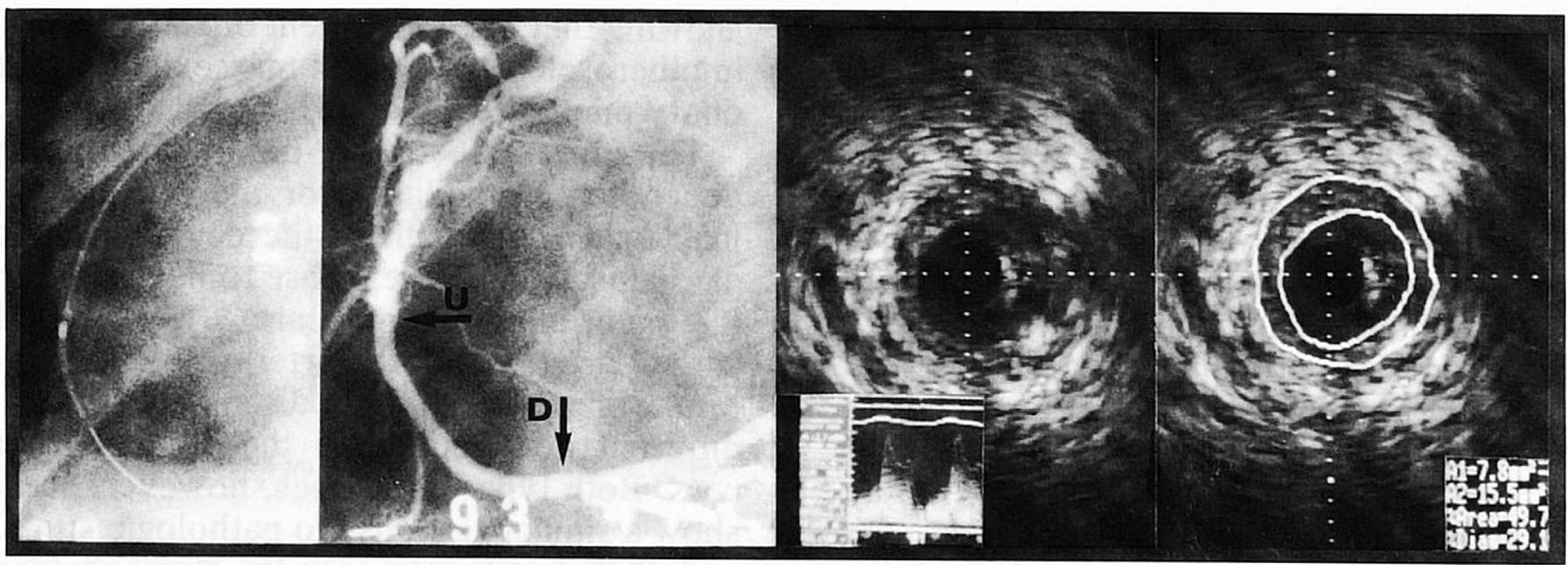

FIG. 4. Simultaneous measurement of flow velocity (position marked $D$ in the angiogram) and lumen cross-sectional area (left panels) in a right coronary artery distal to an intermediate stenosis. The Doppler spectrum is displayed in the lower left corner of the third panel.

irregularities (33) and in angiographically normal segments (34-36) (Fig. 5). Coronary spasm after acetylcholine infusion has also been demonstrated in patients with variant angina, with and without angiographically visible changes $(37,38)$. The observed vasoconstriction or vasodilatation after acetylcholine infusion is the net effect of the conflicting action of this substance on the endothelial cells (stimulation to the release of endothelium-derived relaxing factor) and on the smooth-muscle cells (vasoconstriction due to the direct effect on the cholinergic receptors).

With the use of intracoronary Doppler ultrasonography, an impairment of the endothelium-derived vasodilation was also observed after additional physiological stimuli such as the increase of blood flow (39-41). The flow-dependent vasodilatation is an essential mechanism of adjustment of coronary tone to prevent endothelial damage due to a pathologic increase in wall shear stress $(25,26,40)$. An abnormal vasoconstriction in response to sympathetic stimulation or release of platelet-derived vasoconstrictors (42-44) was observed if the direct effect of these substances on the muscular media was not antagonized by a preserved endotheliummediated vasodilation.

Nitric oxide also has a powerful antiaggregatory activity. Yao et al. (45) showed a protective effect of endogenous nitric oxide in the prevention of cyclic flow variations due to platelet aggregation at the site of endothelial injury. Endothelial dysfunction, therefore, is not only a potential mechanism of ag-

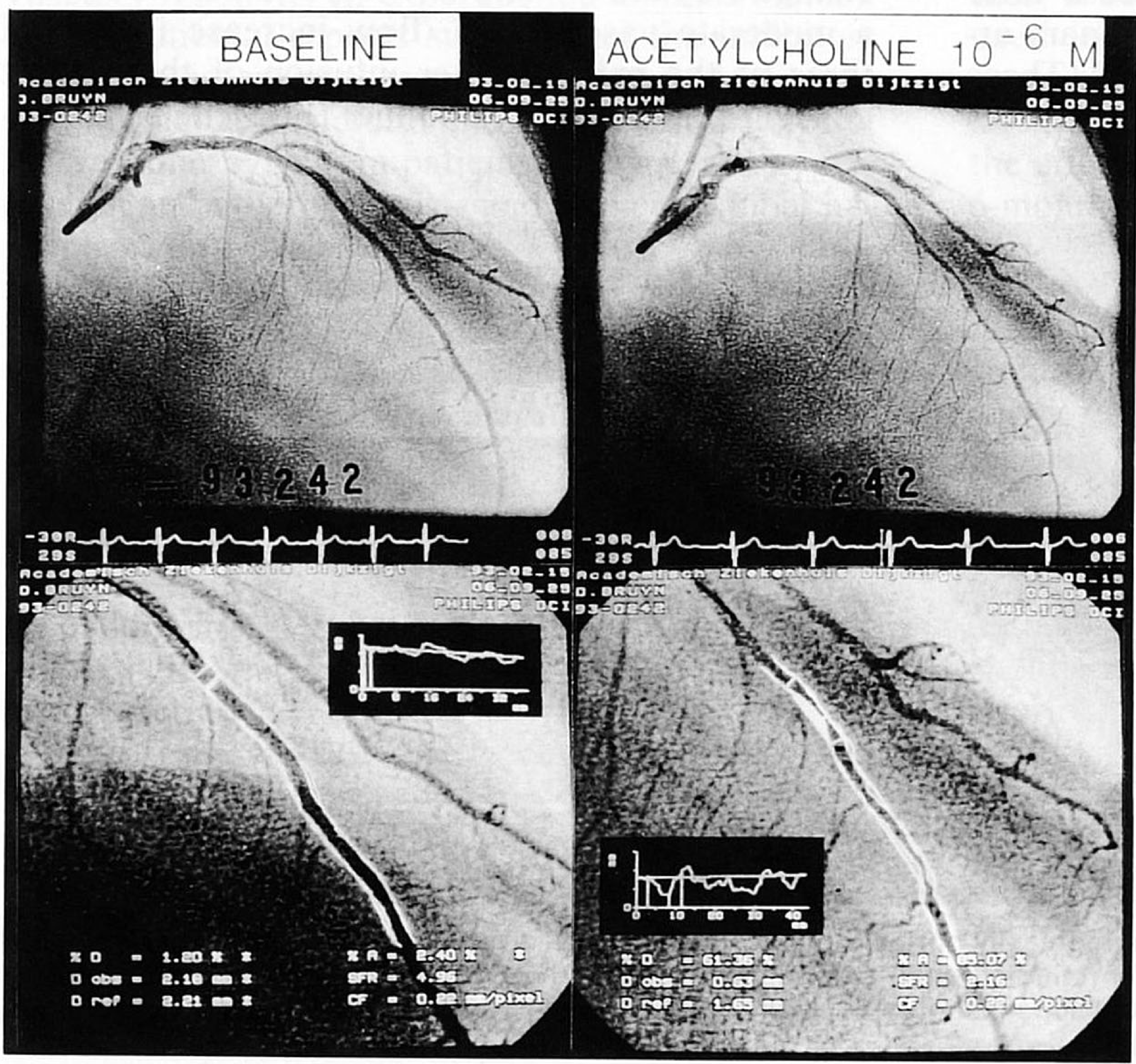

FIG. 5. Upper panels: severe diffuse coronary spasm in the mid-distal segment of an angiographically normal left anterior descending coronary artery at the peak effect of acetylcholine, $10^{-6} \mathrm{M}$. A Doppler guide wire is positioned in the midsegment of the artery. Lower panels: corresponding quantitative angiographic measurements, showing a reduction in the minimal coronary diameter from 2.18 to $0.63 \mathrm{~mm}$. 
gravation of ischemia in patients with coronary atherosclerosis, but it increases the risk of endothelial injury and impairs the antithrombotic reaction, thus facilitating the development of acute coronary syndromes and the release of platelet-derived growth factors that may predispose to progression of atherosclerosis (46). An impairment of endotheliummediated vasodilation has been shown in patients with risk factors for coronary atherosclerosis but without angiographically visible atherosclerotic changes $(35,47)$. A possible limitation of these studies is the poor sensitivity of angiography in the detection of early atherosclerotic changes.

More recently, using two-dimensional intracoronary ultrasonography, the presence of endothelial dysfunction has also been observed in patients with risk factors such as hypertension, hyperlipidemia, family history of coronary artery disease, or smoking but with structurally normal coronary arteries. A complete loss of endothelium-mediated vasodilatation was present in arteries with angiographically visible atherosclerotic changes. Angiographically normal arteries of patients with hypercholesterolemia showed a normal flow-mediated vasodilatation following papaverine infusion but an abnormal vasoconstriction after acetylcholine infusion (48).

The possible presence of opposite effects of acetylcholine infusion on epicardial and resistance coronary arteries has been reported by Hodgson et al. (49). The observed increase of coronary flow after acetylcholine infusion was prevented by pretreatment with methylene blue, an inhibitor of endothelium-derived relaxing factor. Zeiher et al. (50) reported a significantly lower flow increase after acetylcholine infusion in patients with coronary artery disease than in control subjects (Fig. 6). These findings confirmed previous experimental results showing that the impairment of endothelial function in atherosclerotic arteries may extend into the coronary microcirculation (51-53).

The presence of an impaired endotheliumdependent vasodilation of the resistance vessels may induce or facilitate the development of myocardial ischemia in response to neurohumoral stimulation or increased myocardial work (54). The epicardial arteries and the arterioles have large structural differences and, as discussed earlier, show a different involvement in the atherosclerotic process. Both types of arteries, however, are likely to show a similar response to pathologic stimuli of the endothelial cells impairing the intracellular production and release of nitric oxide. The presence of an impaired diffusion or of an increased extracellular degradation of nitric oxide in the thickened intima is a phenomenon limited to the epicardial arteries and may explain an earlier and more severe impairment of the endothelium-mediated vasodilation of these vessels.

An indirect confirmation of this hypothesis is the recently reported variability of impairment of the vasodilatory response to acetylcholine in conductance and resistance vessels (55). In 29 patients undergoing coronary angioplasty, angiographically normal or minimally diseased arteries were studied with quantitative angiography and intracoronary Doppler ultrasonography. Very low doses of acetylcholine $\left(10^{-8} M\right)$ were sufficient to induce a significant coronary vasoconstriction of the epicardial coronary arteries. The resistance vessels, however, showed a variable response, with a significant change only at $10^{-7}$ and $10^{-6} \mathrm{M}$, and a trend toward a moderate vasodilation (flow increase in two of three of the patients after infusion of the highest concentration of acetylcholine) (Fig. 7).

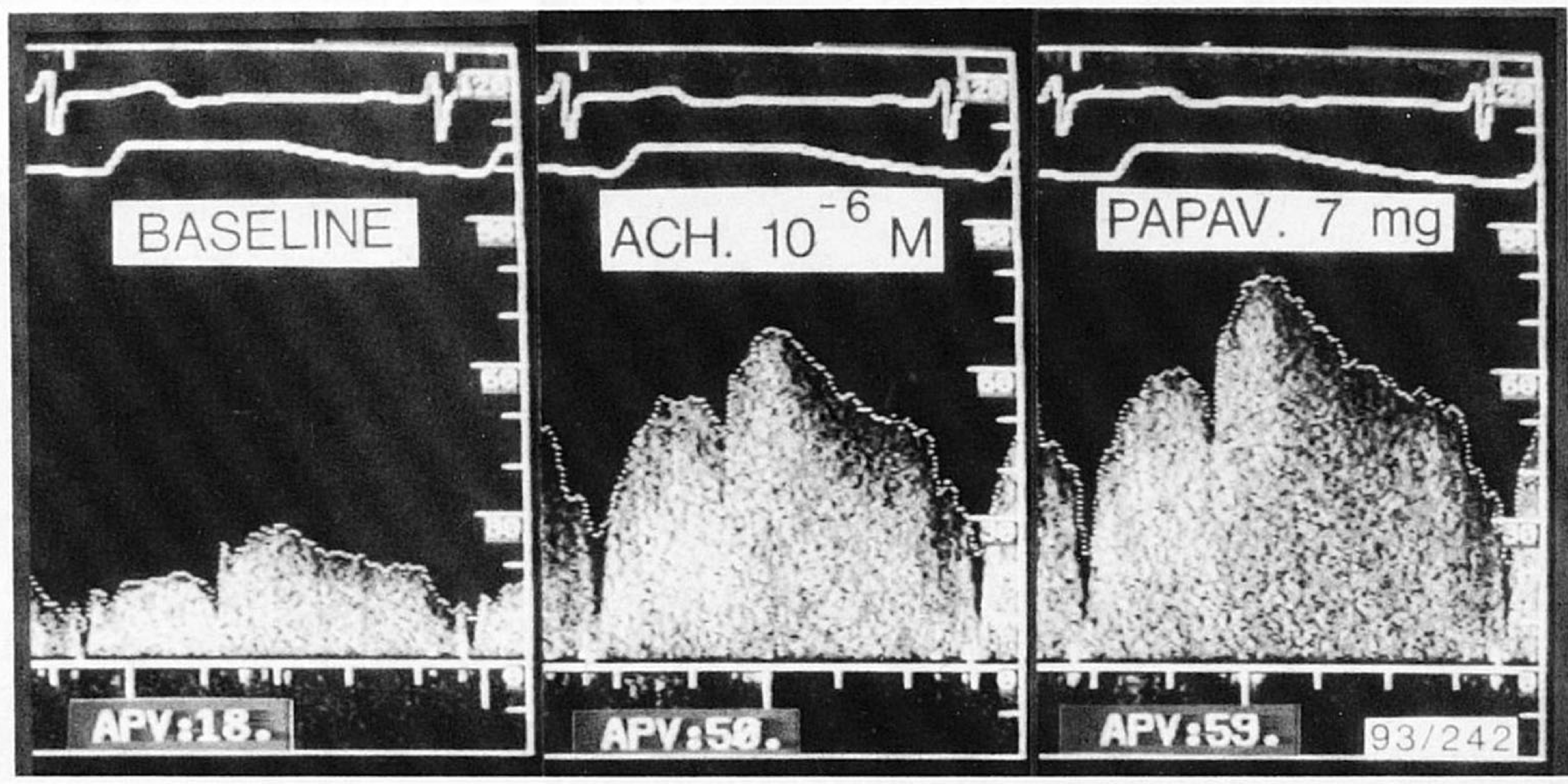

FIG. 6. Flow velocity measurements in an angiographically normal right coronary artery in baseline conditions (left panel) and at the peak effect of acetylcholine $(\mathrm{ACH}) 10^{-6} \mathrm{M}$ (middle panel) and papaverine (PAPAV, right panel) infusions. A more than threefold velocity increase was observed after acetylcholine infusion, with a further increase after papaverine infusion (velocity scale, $120 \mathrm{~cm} / \mathrm{s}$ ). APV, average peak velocity. 

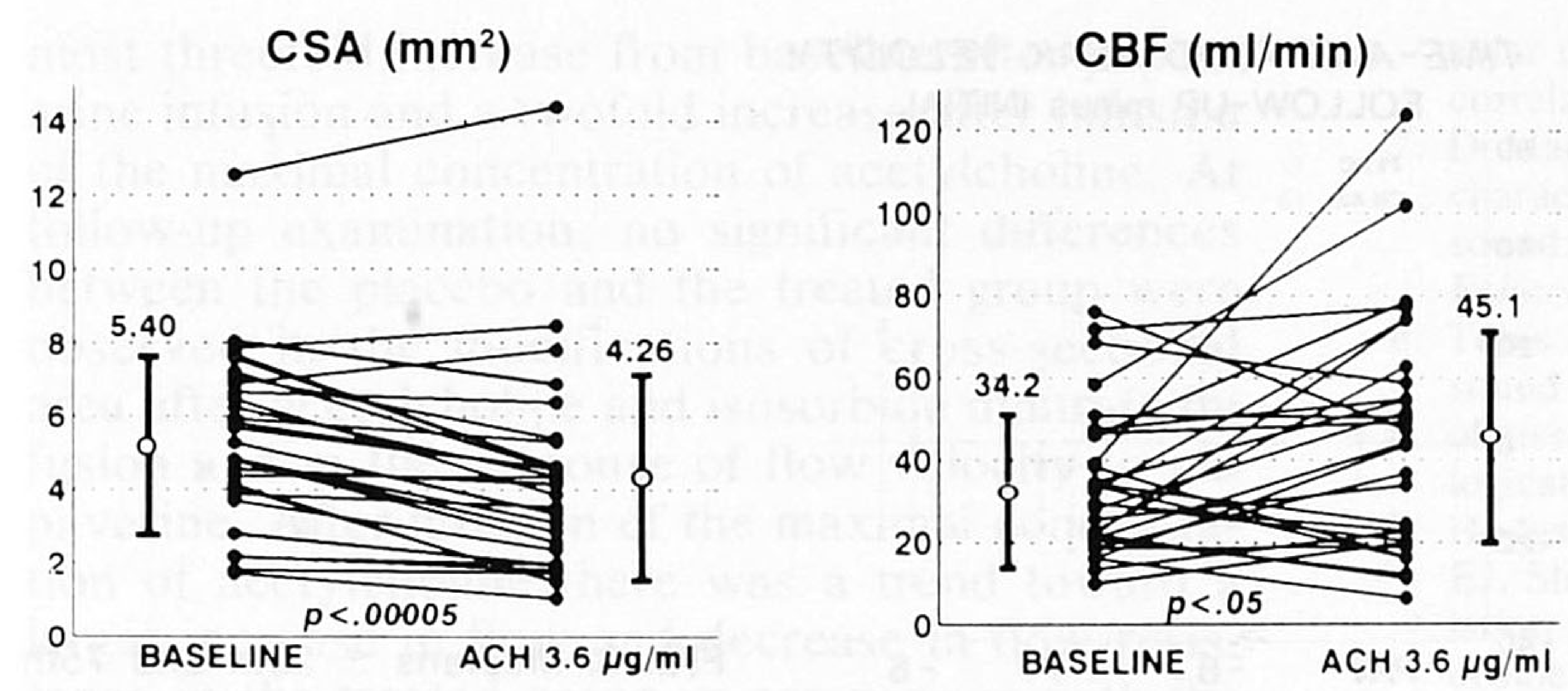

FIG. 7. Cross-sectional area (CSA) and coronary blood flow (CBF) in baseline conditions (baseline 2) and after infusion of the maximal concentration of acetylcholine ( $\mathrm{ACH} 10^{-6} \mathrm{M}$.) Note the almost uniform decrease in cross-sectional area and the large variability of the individual flow change.

\section{ASSESSMENT OF PHARMACOLOGIC VASCULAR PROTECTION}

The following observations have potential clinical implications for the assessment of the effects of pharmacologic interventions.

A prolonged treatment aimed at the regression of the atherosclerotic intimal changes may be required to restore an impaired endothelium-mediated response when the presence of an intimal barrier is the main operative mechanism (56-58). On the contrary, short-term pharmacologic interventions may be sufficient to normalize the endothelial function when metabolic abnormalities are involved. The possibility of normalizing the endothelial response in hypercholesterolemia with a short-term infusion of L-arginine has been shown in animal experiments (59) as well as in human coronary arteries $(60,61)$. Similarly, different classes of drugs have shown the ability to restore a normal endothelium-mediated vascular reactivity in experimental animals $(62,63)$.

Experimental reports suggest that the inhibitors of the angiotensin-converting enzyme (ACE) can also normalize structural and functional changes of the vascular system in patients with arterial hypertension and atherosclerosis and prevent intimal hyperplasia after vascular injury. In spontaneously hypertensive rats, a prolonged therapy with the long-acting ACE inhibitor cilazapril induced a complete normalization of the medial thickness of coronary, renal, carotid, and mesenteric arteries (64). The same pharmacologic agent completely prevented the medial thickening induced in rats by chronic $\beta$-adrenergic stimulation with isoproterenol (65), markedly reduced the neointima formation after balloon injury (66-68), and prevented intimal hyperplasia in a rat model of a venous graft implanted as an arterial conduit (69).

Several mechanisms have been advocated to explain the normalization of the vascular structure and restoration of a normal endothelium-mediated response after treatment with ACE inhibitors: inhibition of the tissue-based (vascular) ACE with a reduced production of angiotensin II, a powerful vasoconstrictive and mitogenic factor. The prevention of the proliferative response reduces the inti- mal thickening that is responsible for a reduced diffusion and increased degradation of the labile nitric oxide before this compound reaches the smoothmuscle cells of the arterial media $(25,26,64,65)$. Another mechanism is the reduced breakdown of circulating bradykinin and unmasking of the effect of the local vascular kallikrein-kinin systems (70-72). This vasodilatory polypeptide can also stimulate the production of endothelium-derived relaxing factor and prostacyclin in an autocrine-paracrine fashion. There is also reduction of the subendothelial infiltration of blood-borne monocytes-macrophages, which inactivates nitric oxide (73).

The experimental data reported earlier, however, cannot be automatically applied to human hypertension and atherosclerosis. The suppression of neointima formation, one of the most interesting properties of this class of drugs, was demonstrated in rats and guinea pigs $(66-69,74)$ but could not be confirmed in rabbits, pigs, and baboons (74-77). Further, it must be noted that the doses per kilogram used in these animal experiments were several times higher than the maximally tolerated doses per kilogram usable in humans. Species specificity of the effect and different dosages may explain why a 6-month treatment with ACE inhibitors was not effective in the prevention of restenosis after percutaneous coronary balloon angioplasty in two large clinical multicenter trials $(78,79)$.

More positive results have been reported in hypertensive patients treated for 4 months with $10 \mathrm{mg}$ of cilazapril and undergoing serial studies with plethysmography (80). The minimal forearm resistance showed a $16 \pm 20 \%$ reduction, whereas no changes were observed after the injection of an endothelium-dependent vasodilator such as acetylcholine. Direct evidence of a normalization of the arteriolar structure in human hypertension was recently obtained using subcutaneous gluteal biopsy before and 1 year after treatment with cilazapril or atenolol (81). A significant reduction $(200-400 \mu \mathrm{m})$ of the media-lumen ratio of the small arteries studied was observed in the cilazapril group whereas no reduction in the media-lumen ratio was observed after atenolol, despite that the treatments were equally effective in lowering the elevated blood 


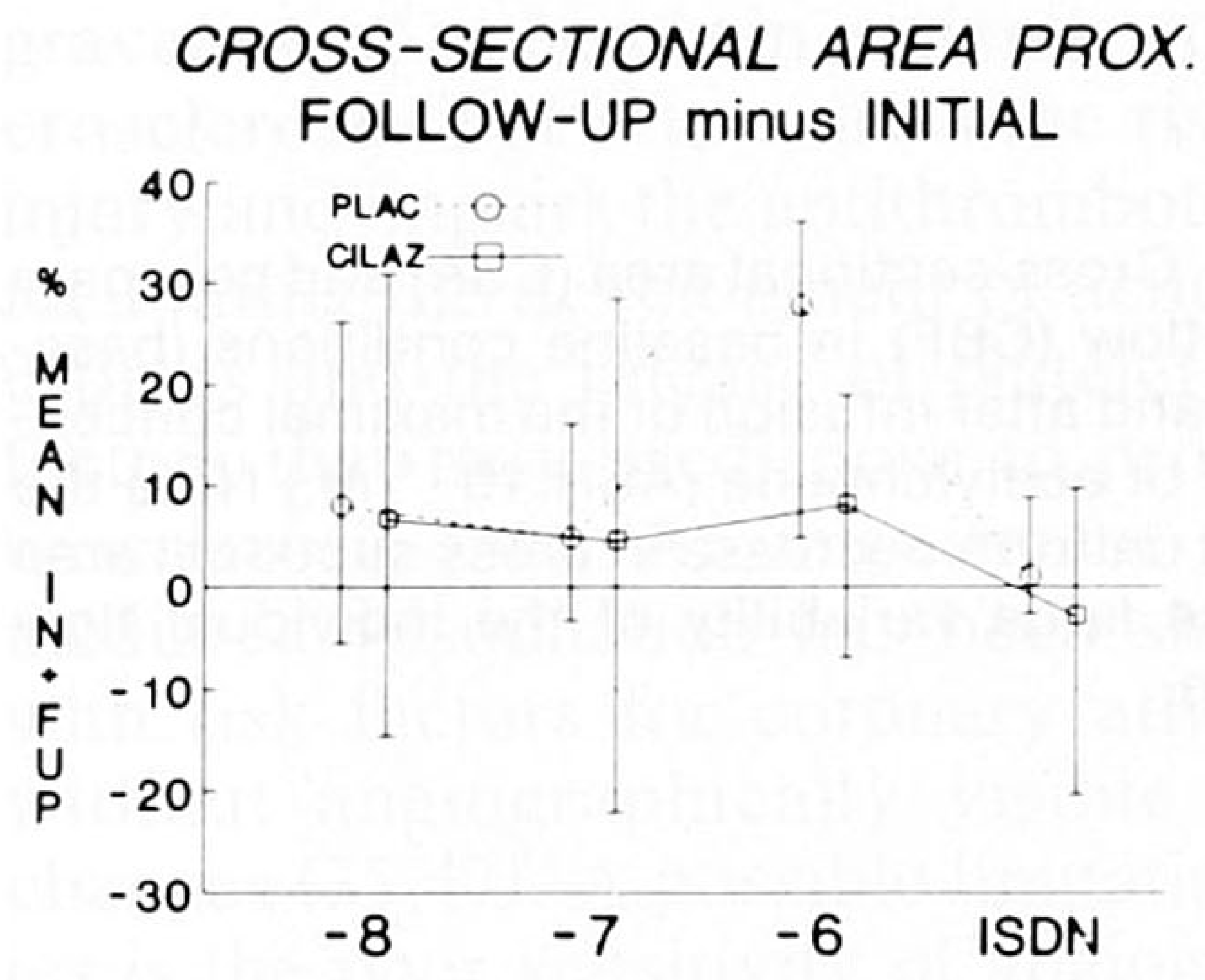

CROSS-SECTIONAL AREA DISTAL FOLLOW-UP minUS INITIAL
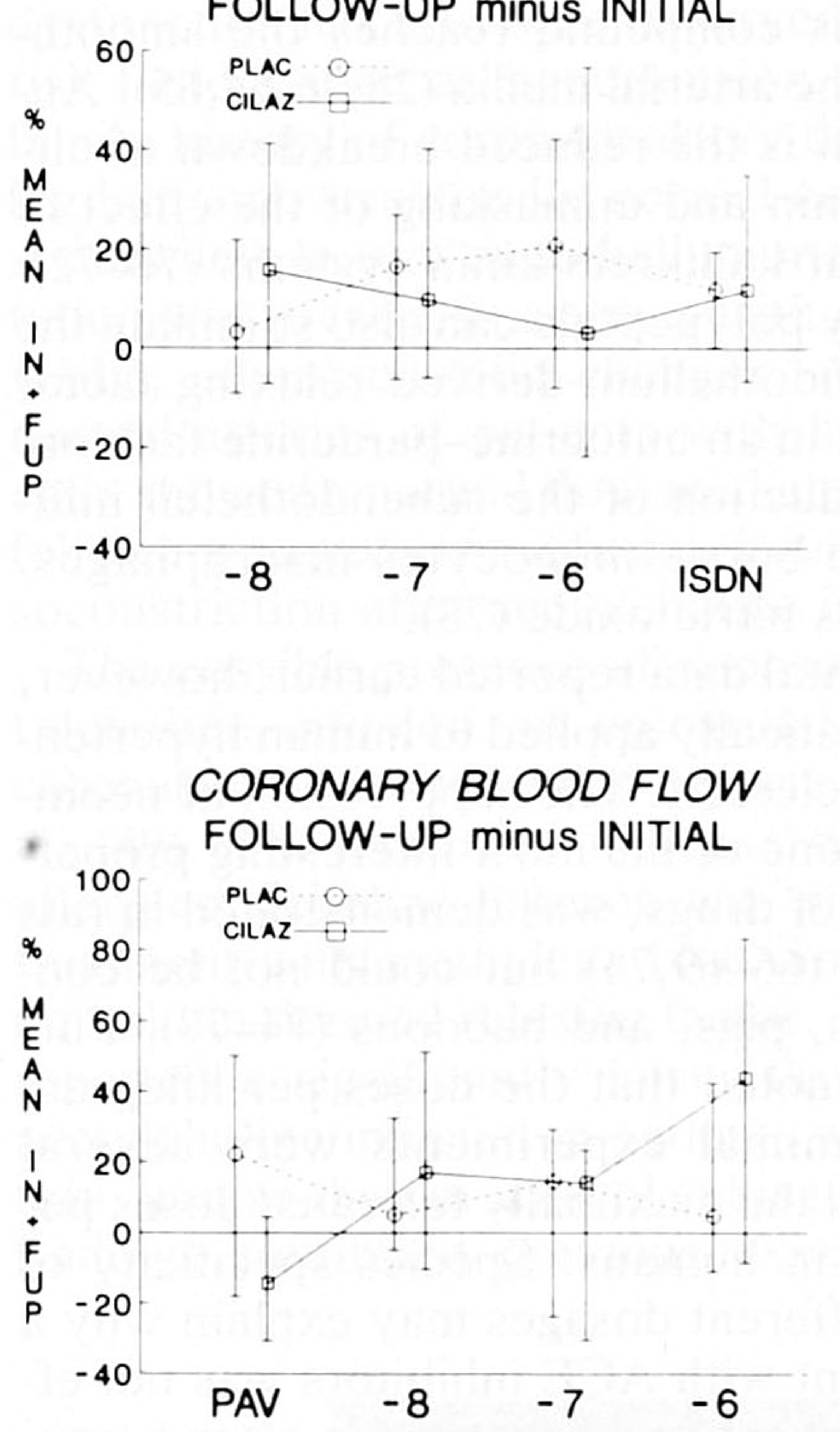
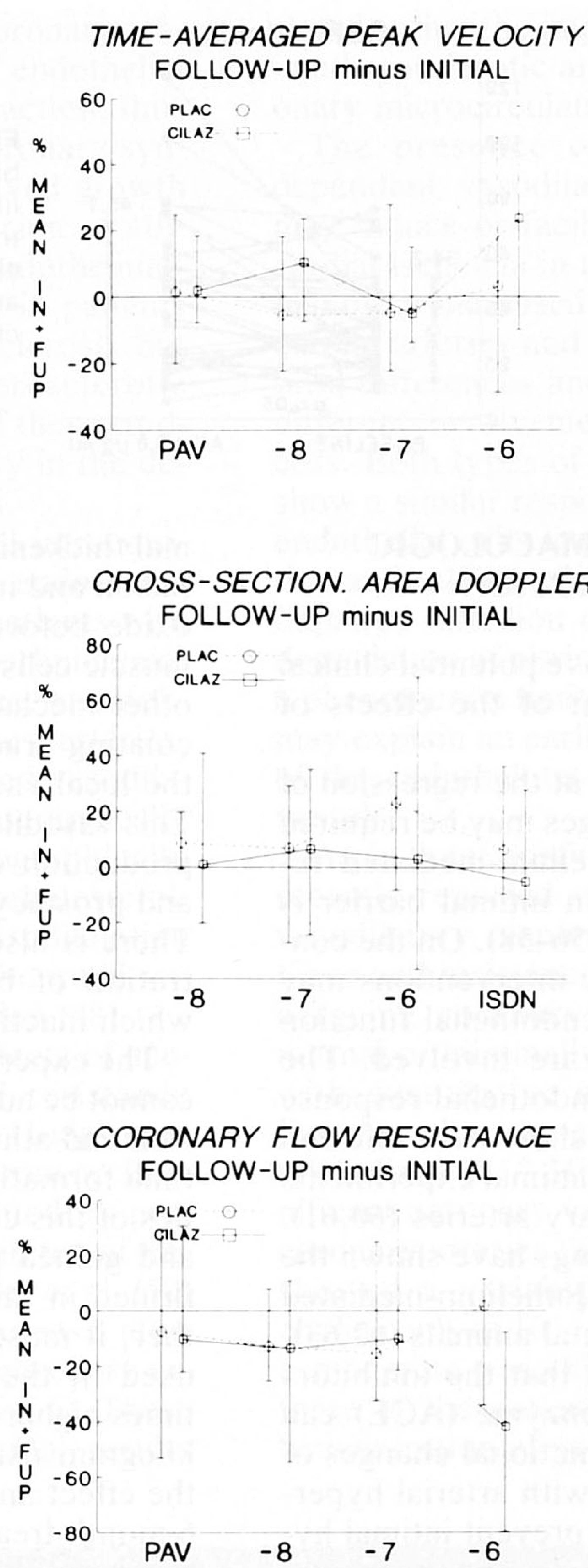

FIG. 8. Medians \pm 25th and 75th percentile of the difference between follow-up (FUP) and initial (IN) measurement, expressed as a percent of the mean of two measurements. $-8,-7$, and -6 indicate the inverse logarithm of the concentration of acetylcholine. ISDN, isosorbide dinitrate; PAV, papaverine; PLA, placebo; CILAZ, cilazapril. The aim of this randomized placebo-controlled parallelgroup double-blind study was the assessment of the effect of a 6month treatment with the angiotensin-converting enzyme inhibitor cilazapril on the response of conductance and resistance coronary arteries to endothelium-dependent and independent vasodilators in patients with coronary artery disease. pressure. In this study, the arterial relaxation after acetylcholine infusion was also improved in the cilazapril group. In the atenolol group no changes were observed after treatment, suggesting that a normalization of the pressure level is not sufficient to correct structural and functional arterial abnormalities. The possibility that similar results can also be obtained in the coronary system can now be studied in vivo in the human catheterization laboratory using quantitative angiography and intracoronary Doppler probes $(23,82,83)$.

The effect of a 6-month treatment with cilazapril on the response of conductance and resistance coronary arteries to endothelium-dependent and independent vasodilators was recently assessed in patients with coronary artery disease in a randomized placebo-controlled, parallel-group, double-blind study. In 34 patients ( $58 \pm 9$ years) undergoing elec- tive percutaneous coronary interventions, a Doppler guide wire was positioned in the proximal segment of a normal or near-normal coronary artery (not $>30 \%$ diameter stenosis). Selective intracoronary infusions of papaverine $(7 \mathrm{mg})$, acetylcholine $(0.036,0.36$, and $3.6 \mu \mathrm{g} / \mathrm{ml}$ at $2 \mathrm{ml} / \mathrm{min})$, and isosorbide dinitrate were performed and a coronary angiogram was acquired for automated quantitative analysis at the peak effect of each infusion. The patients were randomly assigned to receive placebo or cilazapril, $20 \mathrm{mg} / \mathrm{day}$. After 6 months a new study was repeated with the same protocol, and the absolute measurements of cross-sectional area, flow velocity, coronary flow, and flow resistance were compared using a nonparametric test.

In the initial assessment, the cross-sectional area decreased significantly after all three concentrations of acetylcholine. Flow velocity showed an al- 
most threefold increase from baseline after papaverine infusion and a twofold increase after infusion of the maximal concentration of acetylcholine. At follow-up examination, no significant differences between the placebo and the treated group were observed in the modifications of cross-sectional area after acetylcholine and isosorbide dinitrate infusion and in the response of flow velocity to papaverine. After infusion of the maximal concentration of acetylcholine there was a trend toward a larger increase in flow and decrease in flow resistance in the treated group in comparison with the placebo group [coronary flow (median), $45 \%$ increase in the treated group and $4 \%$ in the placebo group; flow resistance (median), $42 \%$ decrease in the treated group and $1 \%$ increase in the placebo group] (Fig. 8). Because of the large individual variability, no significant difference could be demonstrated in spite of the large difference between the two groups.

\section{CONCLUSION}

New intracoronary diagnostic techniques enable us to study in the catheterization laboratory the effects of vascular remodeling in epicardial and resistance coronary vessels. Intracoronary ultrasonography imaging has the unique advantage of the ability to detect and quantify the plaque burden and to study progression and regression of the atherosclerotic plaque. With intracoronary Doppler flow velocity changes due a severe epicardial lesion, an impaired maximal vasodilation of the coronary microvasculature or an impaired endothelium-mediated response can be studied.

These two new complementary techniques may allow the study of pharmacologic interventions in reversing structural and functional changes in human coronary atherosclerosis.

Acknowledgment: Dr. P. N. Ruygrok is the recipient of a National Heart Foundation of New Zealand Training Fellowship. The expert secretarial assistance of Ms. M. Lems and Ms. C. Sprenger de Rover is gratefully acknowledged.

\section{REFERENCES}

1. Pfeffer MA, Braunwald E. Ventricular remodeling after myocardial infarction. Circulation 1990;81:1161-72.

2. Mulvany MJ. Vascular remodeling in hypertension. Eur Heart J 1993;14(suppl C):2-4.

3. Armstrong ML, Heistad DD, Marcus ML, Megan MB, Piegors DJ. Structural and hemodynamic responses of peripheral arteries of macaque monkeys to atherogenic diet. Arteriosclerosis 1985;5:336-46.

4. Glagov S, Weisenberg E, Zairns CK, Stankunavicius R, Kolettis GJ. Compensatory enlargement of human atherosclerotic coronary arteries. $N$ Engl J Med 1987;316:1371-5.

5. Stiel GM, Stiel LSG, Schofer J, Donath K, Mathey DG. Impact of compensatory enlargement of atherosclerotic coronary arteries on angiographic assessment of coronary artery disease. Circulation 1989;80:1603-9.

6. Nishimura RA, Edwards WD, Warness CA, et al. Intravas- cular ultrasound imaging: in vitro validation and pathologic correlation. J Am Coll Cardiol 1990;16:145-54.

7. Di Mario C, Salem HKT, Madretsma S, et al. Detection and characterization of vascular lesions by intravascular ultrasound: an in vitro study correlated with histology. J Am Soc Echocardiogr 1992;5:135-46.

8. Tobis JM, Mallery J, Mahon D, et al. Intravascular ultrasound imaging of human coronary arteries in vivo: analysis of tissue characteristics with comparison to in vitro histological specimens. Circulation 1991;83:913-26.

9. Hodgson JM, Reddy KG, Randeep S, Nair RN, Lesnefsky EJ, Sheehan HM. Intracoronary ultrasound imaging: correlation of plaque morphology with angiography, clinical syndrome and procedural results in patients undergoing coronary angioplasty. J Am Coll Cardiol 1993;21:35-44.

10. Hermiller JB, Tenaglia AN, Kisslo $\mathrm{KB}$, et al: In vivo validation of compensatory enlargement of atherosclerotic coronary arteries. Am J Cardiol 1993;71:665-8.

11. Baptista J, Di Mario C, Serruys PW, et al. Correlation of quantitative angiography and dobutamine stress echocardiography. J Am Coll Cardiol 1994;23:1434-9.

12. White CW, Wright CB, Doty DB, et al. Does visual interpretation of the coronary arteriogram predict the physiologic significance of a coronary stenosis? N Engl J Med 1984;310: 819-24.

13. Vos J, de Feyter PJ, Simoons ML, Tijssen JGP, Deckers JW. Retardation and arrest of progression or regression of coronary artery disease: a review. Progr Cardiovasc Dis 1993;35:435-54.

14. Lassetter JE, Krall RC, Moddrelle DS, Jenkin RD. Morphologic changes of the arterial wall during regression of experimental atherosclerosis [Abstract]. Circulation 1992;86:I518.

15. Gupta M, Connolly AJ, Zhu BQ, et al. Quantitative analysis of progression of atherosclerosis by intravascular ultrasound: validation in a rabbit model [Abstract]. Circulation 1992;86:I-518.

16. Crawford T, Levene CI. Medical thinning in atheroma. $J$ Pathol 1953;66:19-23.

17. Vita JA, Treasure CB, Ganz P, Cox DA, Fish RD, Selwyn AP. Control of shear stress in the epicardial coronary arteries of humans: impairment by atherosclerosis. J Am Coll Cardiol 1989;14:1193-9.

18. Zairns CK, Zatina MA, Giddens DP, Ku DN, Glagov S. Shear stress regulation of artery lumen diameter in experimental atherogenesis. J Vasc Surg 1987;5:413-20.

19. Chilian WM, Eastham CL, Marcus ML. Microvascular distribution of coronary vascular resistance in the beating left ventricle. Am J Physiol 1986;251:H779-88.

20. Chilian WM, Kuo L, Defily DV, Jones CJH, Davis MJ. Endothelial regulation of coronary microvascular tone under physiological and pathological conditions. Eur Heart $J 1993$; 14(suppl 1):55-9.

21. Schwartzkopf B, Motz W, Frenzel H, Vogt M, Knauer S, Strauer BE. Structural and functional alterations of the intramyocardial coronary arterioles in patients with arterial hypertension. Circulation 1993;88:993-1003.

22. Sanz ML, Mancini GBJ, Lefree MT, et al. Variability of quantitative digital subtraction coronary angiography before and after percutaneous transluminal coronary angioplasty. Am J Cardiol 1987;60:55-60.

23. Serruys PW, Di Mario C, Kern M. Intracoronary Doppler. In: Topol E, ed. Textbook of interventional cardiology, 2nd ed. Philadelphia: WB Saunders, 1993:1069-121.

24. Sudhir K, MacGregor JS, Barbant SD, et al. Assessment of coronary conductance and resistance vessel reactivity in response to nitroglycerin, ergonovine and adenosine: in vivo studies with simultaneous intravascular two-dimensional and Doppler ultrasound. J Am Coll Cardiol 1993;21:1261-8.

25. Rubanyi GM. The role of endothelium in cardiovascular homeostasis and diseases. J Cardiovasc Pharmacol 1993;22 (suppl 4):S1-14. 
26. Bassenge E, Busse R. Endothelial modulation of coronary tone. Prog Cardiovasc Dis 1988;30:349-80.

27. Furchgott RF, Zawadzki JV. The obligatory role of endothelial cells in the relaxation of smooth muscle by acetylcholine. Nature 1980;288:373-6.

28. Palmer RM, Ashton DS, Moncada S. Vascular endothelial cells synthetize nitric oxide from L-arginine. Nature 1988; 333:664-6.

29. Vallance P, Collier J, Moncada S. Effects of endotheliumderived nitric oxide on peripheral arteriolar tone in man. Lancet 1989;2:997-1000.

30. Panza JA, Quyyumi AA, Brush JEJR, et al. Abnormal endothelium-dependent vascular relaxation in patients with essential hypertension. $N$ Engl J Med 1990;323:22-7.

31. Johnstone MT, Gallagher SJ, Scales KM, Cusco JA, Lee B, Creager MA. Endothelium-dependent vasodilatation is impaired in patients with insulin-dependent mellitus [Abstract]. Circulation 1992;86:I-618.

32. Fostermann U, Mugge A, Alheid U, et al. Selective attenuation of endothelium-mediated vasodilatation in atherosclerotic human coronary arteries. Circ Res 1988;62:185-90.

33. Ludmer PL, Selwyn AP, Shook TL, et al. Paradoxical vasoconstriction induced by acetylcholine in atherosclerotic coronary arteries. $N$ Engl J Med 1986;315:1046-51.

34. Werns SD, Walton JA, Hsia HH, et al. Evidence of endothelial dysfunction in angiographically normal coronary arteries of patients with coronary artery disease. Circulation 1989;79:287-91.

35. Vita JA, Treasure CB, Nabel EG, et al. Coronary vasomotor response to acetylcholine relates to risk factors in coronary artery disease. Circulation 1990;81:491-7.

36. Yasue H, Matsuyama K, Okumura K, et al. Responses of angiographically normal human coronary arteries to intracoronary injection of acetylcholine by age and segment. Circulation 1990;81:482-90.

37. Okumara K, Yasue H, Matsuyama T, et al. A study of coronary hemodynamics during acetylcholine induced coronary spasm in patients with variant angina: endotheliumdependent dilatation in the resistance vessels. $J$ Am Coll Cardiol 1992;19:1426-34.

38. Vrints CJM, Bult H, Hitter E, Herman AG, Snoeck JP. Impaired endothelium-cholinergic coronary vasodilatation in patients with angina and normal coronary arteriograms. $J$ Am Coll Cardiol 1992;19:21-31.

39. Cox DA, Vita JA, Treasure CB, et al. Atherosclerosis impairs flow-mediated dilation of coronary arteries in humans. Circulation 1989;80:458-65.

40. Nabel EG, Selwyn AP, Ganz P. Large arteries in humans are responsive to changing blood flow: an endotheliumdependent mechanism that fails in patients with atherosclerosis. J Am Coll Cardiol 1990;16:349-56.

41. Drexler H, Zeiher AM, Wollschlager H, Meinertz T, Just H, Bonzel T. Flow-dependent coronary artery dilatation in humans. Circulation 1989;80:466-74.

42. Zeiher AM, Drexler H, Wollschlager $\mathrm{H}$, et al. Coronary vasomotion in response to sympathetic stimulation in humans: importance of the functional integrity of the endothelium. $J$ Am Coll Cardiol 1989;14:1181-90.

43. McFadden EP, Clarke JG, Davies GJ, et al. Effect of intracoronary serotonin on coronary vessels in patients with stable angina and in patients with variant angina. $N$ Engl J Med 1991;342:648-54.

44. Zeiher AM, Schachinger V, Weitzel SH, et al. Intracoronary thrombus formation causes focal vasoconstriction of epicardial arteries in patients with coronary artery disease. Circulation 1991;83:1519-25.

45. Yao SK, Ober JC, Willerson JT, et al. Endogenous nitric oxide protects against platelet aggregation and cyclic flow variations in stenosed and endothelium injured arteries. Circulation 1992;86:1302-9.

46. Meredith IT, Yeung AC, Weidinger FF, et al. Role of impaired endothelium-dependent vasodilation in ischaemic manifestations of coronary artery disease. Circulation 1993; 87(suppl V): V56-66.

47. Zeiher AM, Drexler H, Wollschlager H, Just H. Modulation of coronary vasomotor tone in humans. Progressive endothelial dysfunction with different early stages of coronary atherosclerosis. Circulation 1991;83:391-401.

48. Hodgson J, Nair R, Sheehan HM, Reddy KG. Endothelial dysfunction in coronary arteries precedes ultrasonic evidence of atherosclerosis in patients with risk factors [Abstract]. J Am Coll Cardiol 1992;19:323A.

49. Hodgson JB, Marshall JJ. Direct vasoconstriction and endothelium-dependent vasodilation. Circulation 1989;79: 1043-51.

50. Zeiher AM, Drexler H, Wollschläger H, Just H. Endothelial dysfunction of the coronary microvasculature is associated with impaired coronary blood flow regulation in patients with early atherosclerosis. Circulation 1991;84:1984-92.

51. Selke FW, Armstrong ML, Harrison DG. Endotheliumdependent vascular relaxation is abnormal in the coronary microcirculation of atherosclerotic primates. Circulation 1990;81:1586-93.

52. Chilian WM, Dellsperger KC, Layne SM, et al. Effects of atherosclerosis on the coronary microcirculation. Am J Physiol 1990;258:H-529-39.

53. Yamamoto H, Bossalier C, Cartwright J, Henry PD. Videomicroscopic demonstration of defective cholinergic arteriolar vasodilatation in atherosclerotic rabbit. J Clin Invest 1988;81:1752-8.

54. Chesebro JH, Fuster V, Webster MWI. Endothelial injury and coronary vasomotion. J Am Coll Cardiol 1989;14: 1191-2.

55. Di Mario C, Strikwerda S, Gil R, de Feyter PJ, de Jaegere P, Serruys PW. Response of conductance and resistance coronary vessels to scalar concentrations of acetylcholine: assessment with quantitative angiography and intracoronary Doppler in 29 patients with coronary artery disease. Am Heart J 1994;127:514-31.

56. Harrison DG, Armstrong ML, Freiman PC, Heistad DD. Restoration of endothelium-dependent relaxation by dietary treatment of atherosclerosis. J Clin Invest 1987;80:1808-11.

57. Fleischauer FJ, Yan WD, Fischell TA. Fish oil improves endothelium-dependent coronary vasodilatation in heart transplant recipients. J Am Coll Cardiol 1993;21:982-9.

58. Panza JA, Quyyumi AA, Callahan TS, Epstein SE. Effect of antihypertensive treatment on endothelium-dependent vascular relaxation in patients with essential hypertension. $J$ Am Coll Cardiol 1993;21:1145-51.

59. Cooke JP, Andon NA, Girerd XJ, Hirsch AT, Creager MA. Arginine restores cholinergic relaxation of hypercholesterolemic rabbit thoracic aorta. Circulation 1991;83:1057-62.

60. Drexler H, Zeiher AM, Meinzer K, Just H. Correction of endothelial dysfunction in coronary microcirculation of hypercholesterolemic patients by L arginine. Lancet 1991;338: 1546-51.

61. Dubois-Randé JL, Zelinsky R, Roudot F, et al. Effects of infusion L-arginine into the left anterior descending coronary artery on acetylcholine-induced vasoconstriction of human atheromatous coronary arteries. Am J Cardiol 1992;70:126975.

62. Dohi Y, Criscione L, Pfeiffer K, Luscher TF. Normalization of endothelial dysfunction of hypertensive mesenteric resistance arteries by chronic therapy with benazepril or nifedipine [Abstract]. J Am Coll Cardiol 1992;19:226A.

63. Williams JK, Adams MR, Herrington DM, Clarkson TB Short-term administration of estrogen and vascular responses of atherosclerotic coronary arteries. J Am Coll Cardiol 1992;20:452-7.

64. Clozel JP, Kuhn H, Hefti F. Decreases of vascular hypertrophy in four different types of arteries in spontaneously hypertensive rats. Am J Med 1989;87(suppl 6):92S-5S.

65. Roux S, Clozel JP, Fischli W, Kuhn H. Isoproterenol impairs the rat coronary vasculature: effects of angiotensin- 
converting enzyme inhibition. J Cardiovasc Pharmacol 1992;19:525-31.

66. Osterrieder W, Muller RKM, Powell JS, Clozel JP, Hefti F, Baumgartner HR. Role of angiotensin II in injury-induced neointima formation in rats. Hypertension 1991;18(suppl 2): II-60-4.

67. Clozel JP, Muller RKM, Dipl N, Roux S, Filschi W, Baumgartner HR. Influence of the status of renin-angiotensin system on the effect of cilazapril on neo-intima formation after vascular injury in rats. Circulation 1993;88:1222-7.

68. Lehmann K, Powell JS. Effect of cilazapril on the proliferative response after vascular damage. $J$ Cardiovasc Pharmacol 1993;22(suppl 4):S19-24

69. Roux SP, Clozel JP, Kuhn H. Cilazapril inhibits wall thickening of vein bypass graft in the rat. Hypertension 1991;18 (suppl 2):II43-6.

70. Hecker M, Bara AT, Busse R. Angiotensin-converting enzyme inhibitor unmasks endogenous kinin production by bovine coronary artery endothelium. Eur Heart J 1993;14 (suppl 1):161-3.

71. Hecker M, Dambacher T, Busse R. Role of endotheliumderived bradykinin in the control of vascular tone. J Cardiovasc Pharmacol 1992;20(suppl 9):S55-61

72. Auch-Schwelk W, Bossaller C, Claus M, Graf K. Grafe M Fleck E. Local potentiation of bradykinin-induced vasodilatation by converting-enzyme inhibition in isolated coronary arteries. J Cardiovasc Pharmacol 1992;20(suppl 9):S62-7.

73. Clozel M, Kuhn H, Hefti F, Baumgartner HR. Endothelial dysfunction and subendothelial monocytes macrophages in hypertension: effect of angiotensin converting enzyme inhibition. Hypertension 1991;18:132-41.

74. Clozel JP, Hess P, Michael C, Schietinger K, Baumgartner HR. Inhibition of converting enzyme and neointima formation after vascular injury in rabbits and guinea pigs. Hypertension 1991;18(suppl 2):II55-9.

75. Lam JYT, Bourassa MG, Blaine L, Lachapelle C. Can cilazapril reduce the development of atherosclerotic changes in balloon injured porcine carotid arteries [Abstract]? Circulation 1990;82(suppl III):III-429.

76. Churchill DA, Siegel CO, Dougherty KG, Raizner A, Minor ST. Failure of enalapril to reduce coronary restenosis in a swine model [Abstract]. Circulation 1991;84(suppl II):II297.

77. Hanson SR, Powell JS, Dodson T, Lumsden A, Kelly AB, Anderson JS. Effects of angiotensin converting enzyme inhibition with cilazapril on intimal hyperplasia in injured arteries and vascular grafts in the baboon. Hypertension 1991; 18(suppl II):II-70-6.

78. The Mercator Study Group. Does the new angiotensin converting enzyme inhibitor cilazapril prevent restenosis after percutaneous transluminal coronary angioplasty? Circulation 1992;86:100-10.

79. The Marcator Study Group. The effect of high dose angiotensin converting enzyme on restenosis: the final results of the MARCATOR study: a multicenter double blind placebo controlled trial of cilazapril [Abstract]. Circulation 1992;86:I-53.

80. Kiowski W, Linder L, Nuesch R, Martina B. Effects of angiotensin converting enzyme inhibition on endothelial vasodilator function in primary human hypertension. Eur Heart J 1993;14(suppl C):5-9.

81. Schiffrin EL, Deng LY, Larochelle P. Effects of antihypertensive treatment on vascular remodeling in essential hypertensive patients. J Cardiovasc Pharmacol 1994;24(suppl 3): S51-6 (this issue).

82. Doucette JW, Douglas Corl P, Payne HP, et al. Validation of a Doppler guide wire for intravascular measurement of coronary artery flow velocity. Circulation 1992;85:1899-911.

83. Serruys PW, Di Mario C, Meneveau N, et al. Intracoronary pressure and flow velocity from sensor-tip guidewires. A new methodological comprehensive approach for the assessment of coronary hemodynamics before and after coronary interventions. Am J Cardiol 1993;71:41-53. 